\title{
C-Cr Associates and Carbide Precipitation in Manet Steel
}

\author{
P. Gondi, R. Montanari and M.E. Tata
}

Dip. Ingegneria Meccanica, Università di Roma "Tor Vergata", Via della Ricerca Scientifica s.n.c., O0133 Roma, Italy

\begin{abstract}
Intcrnal friction (IF) data show that the evolution of $\mathbf{C}-\mathrm{Cr}_{\mathrm{n}}$ associate distribution of MANET steel is connected to the $\mathrm{Cr}$-rich carbides $\left(\mathrm{M}_{7} \mathrm{C}_{3}\right.$ and $\left.\mathrm{M}_{23} \mathrm{C}_{6}\right)$ precipitation. Carbides extracted from the matrix have been investigated by $\mathrm{X}$-ray diffractometry and EDS microanalysis measurements. It is discussed the hypothesis that the $\mathrm{M}_{7} \mathrm{C}_{3}$ carbides form by aggregation of $\mathrm{C}-\mathrm{Cr}_{1}$ associates.
\end{abstract}

\section{INTRODUCTION}

Phenomena of solute segregation induced by thermal treatments and/or irradiation have been extensively investigated in $\mathrm{Fe}-\mathrm{Cr}$ based alloys by means of different experimental techniques: small angle neutron scattering [1,2], Mössbauer spectroscopy [3,4], TEM [5] and field ion microscopy [6,7]. The presence of $C$ in these alloys strongly influences the segregation processes and in addition gives rise to the precipitation of carbides.

IF experiments made by Gondi et al.[8,9] on $\mathrm{Cr}$ martensitic steels showed that $\mathrm{C}-\mathrm{Cr}_{\mathrm{n}}$ associates are present in the as-quenched materials with a distribution mainly depending on the $\mathrm{Cr}$ content and on the cooling rate from the austenitic phase. Different types of associates correspond to a different number $\mathbf{n}$ ( from 0 to 6 ) of $\mathrm{Cr}$ atoms, which occupy the corners of the octahedron around the Catom. C-Cr ${ }_{\mathrm{n}}$ associates are characterized by different binding energies for the $C$ atom and the IF spectrum can be considered as sum of seven Snoek-type peaks with relaxation strengths $\Delta_{n}$ depending on the associate distribution.

Investigations on MANET steel have shown that the $C-\mathrm{Cr}_{n}$ associates play a fundamental role on the austenite $\rightarrow$ martensite transformation [10] and influence the mechanical stability, in particular the fracture behaviour and the ductile to brittle transition, when the material is subjected to thermal treatments [11]. Therefore, $\mathrm{C}-\mathrm{Cr}_{\mathrm{n}}$ associates have to be considered microstructural features of the utmost importance for the mechanical behaviour of MANET steel and in general of $\mathrm{Cr}$ martensitic steels, candidate materials for structural applications in future fusion reactors [11].

The aim of the present work is to determine whether the $\mathrm{C}-\mathrm{Cr}_{\mathrm{n}}$ associates affect the precipitation of $\mathrm{Cr}$ carbides and, in this case, to assess which is their specific role in the process.

\section{EXPERIMENTAL.}

The investigated MANET steel has the following chemical composition: $\mathrm{C} 0.17, \mathrm{Cr} 10.5, \mathrm{Mo} 0.50, \mathrm{Ni} 0.85$, Mn 0.60, Nb 0.20, V 0.25, Si 0.32, Al 0.05, N 0.003, P 0.005 and Fe to balance (wt\%).

After the austenitization treatment $\left(1.8 \times 10^{3} \mathrm{~s}\right.$ at $\left.1348 \mathrm{~K}\right)$, the material has been cooled down to room temperature with a rate $\dot{T}=150 \mathrm{~K} \mathrm{~min}^{-1}$ and then subjected to a thermal treatment consisting of successive heating steps of $3.6 \times 10^{3} \mathrm{~s}$ at $373,473,573,673,773$ and $873 \mathrm{~K}$.

IF and dynamic modulus $\left(M_{d}\right)$ measurements have been carried out after each heating step. IF tests were made using the method of frequency modulation in the T range $300-873 \mathrm{~K}$ with a nearly constant heating rate $\left(2 \mathrm{~K} \mathrm{~min}^{-1}\right)$. The $\mathrm{Q}^{-1}$ values were determined from the logarithmic decay of flexural vibrations with resonance frequency $\mathrm{f}-250 \mathrm{~Hz}$. The strain amplitude was kept below $1 \times 10^{-6}$.

After each step of thermal treatment the carbides have been extracted from the metal matrix by using an electrochemical method, then they have been investigated by X-ray diffractometry (XRD) and SEM observations with EDS microanalysis. The electrochemical method employed a cell operating at room temperature with a solution of $\mathrm{HCl}(10 \%)$ in methanol, cathod of INOX steel, tension $1.5 \mathrm{~V}$ and current 0.5 A. The filtering was made using Durapore membrane filters with pores of $0.1 \mu \mathrm{m}$. XRD spectra of carbides have been recorded using $M o K \alpha$ radiation in the $2 \theta$ range $5-50^{\circ}$. Precision line profiles were obtained by step-scanning with $2 \theta$ intervals of $0.005^{\circ}$ and counting times of $20 \mathrm{~s}$ for each step. 


\section{RESULTS}

Fig.1 shows the $Q^{-1}$ curves after the heating steps at 673,773 and $873 \mathrm{~K}$.

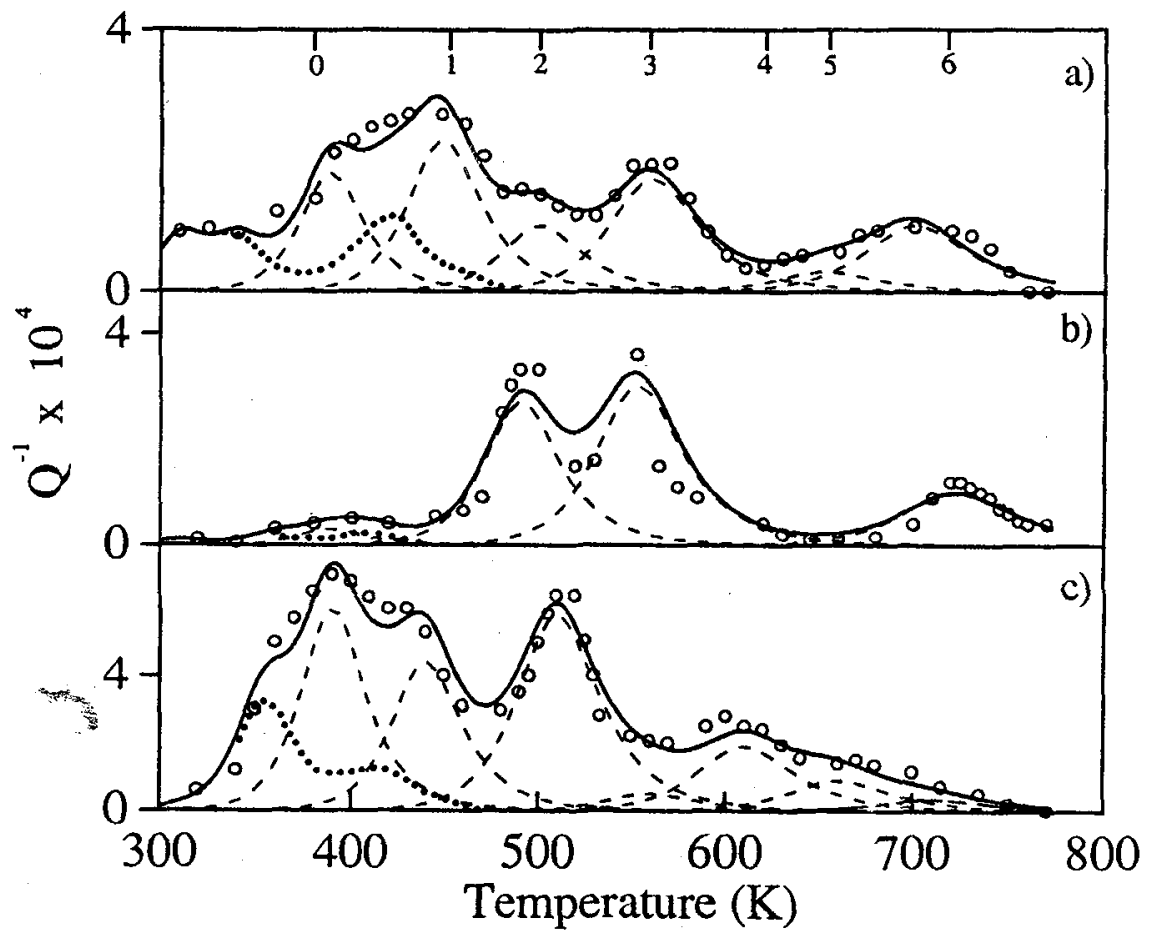

Figure 1- IF spectra of MANET steel after the heating steps at $673 \mathrm{~K}$ (a), $773 \mathrm{~K}$ (b) and $873 \mathrm{~K}$ (c). The markers indicate the central positions of the $\mathrm{Q}^{-1}$ peaks.

The IF spectra have been fitted (solid line) using as reference the activation energies $H_{n}$ given for ternary $\mathrm{Fe}-\mathrm{Cr}-\mathrm{C}$ alloys by the theoretical model of Tomilin et al.[12] :

$Q^{-1}=\sum_{n=0}^{6} Q_{n}^{-1}=\sum_{n=0}^{6} \frac{\Delta_{n}}{2} \cdot \operatorname{sech}\left[\left(\frac{H_{n}}{R}\right) \cdot\left(\frac{1}{T}-\frac{1}{T_{n}}\right)\right]$

$H_{n}=H_{0}+n \cdot \Delta H$

$H_{0}=8.37 \times 10^{4} \mathrm{~J} /$ mole is the activation energy when only Fe atoms are present at the corners of the octahedron and a contribution $\Delta H=1.30 \times 10^{4} \mathrm{~J} / \mathrm{mole}$ has to be added to $H_{0}$ for every $\mathrm{Cr}$ atom that substitutes an $\mathrm{Fe}$ atom. The central temperatures $T_{n}$ of the $Q^{-1}$ peaks calculated for the experimental resonance frequency $f$ $=250 \mathrm{~Hz}$ are in Tab.1. Some difficulties to fit IF spectra arise since MANET steel is more complex than a Fe-Cr-C alloy: it contains other alloying elements ( $\mathrm{Nb}, \mathrm{Mo}, \mathrm{Mn}, \mathrm{V}$ etc.), which cause shifts of peak positions respect the theoretical $\mathrm{T}_{\mathrm{n}}$ values. Furthermore these elements are present in minor concentration in $\mathrm{Nb}$-rich and $\mathrm{Cr}$-rich carbides and EDS microanalysis measurements show that their percentages present some variations depending on the temperature of thermal treatment. Since it is not possible to take into account all these effects and thus determine exactly the central temperatures of $Q^{-1}{ }_{n}$ peaks, shifts of the peak positions around the calculated values $T_{n}$ have been considered to get the best fit curve of experimental data.

As reported in detail in ref.[13], the IF spectrum presents components due to $\mathrm{N}$ relaxation processes. The $\mathrm{N}$ components correspond approximately to the IF peaks observed in $\mathrm{Fe}-\mathrm{Cr}-\mathrm{N}$ alloys by Ritchie and Rawlings [14] and attributed to $\mathrm{N} / \mathrm{Cr}-\mathrm{Cr}, \mathrm{Fe}-\mathrm{N}$ and $\mathrm{N} / \mathrm{Fe}-\mathrm{Cr}$ interactions. 
The total $\mathrm{N}$ contribution is indicated in fig. 1 by a dotted line. The heigths of the $\mathrm{Q}^{-1}$ snoek-type peaks due to $\mathrm{C}$ relaxation processes are given in Tab.1.

Table 1- Heigths of the $Q^{-1}$ Snoek-type peaks due to $\mathrm{C}$ relaxation processes after the heating steps at 673,773 and $873 \mathrm{~K}$. The central temperatures $T_{n}$ of the peaks are reported.

\begin{tabular}{|c|c|c|c|c|}
\hline Peak & $\mathbf{T}_{\mathrm{n}}(\mathrm{K})$ & $673 \mathrm{~K} \mathrm{step}$ & $773 \mathrm{~K} \mathrm{step}$ & $873 \mathrm{~K} \mathrm{step}$ \\
\hline$Q^{-1}{ }_{0}$ & 380 & $1.8 \times 10^{-4}$ & $3.0 \times 10^{-5}$ & $6.0 \times 10^{-4}$ \\
\hline$Q^{-1}{ }_{1}$ & 453 & $2.3 \times 10^{-4}$ & - & $4.4 \times 10^{-4}$ \\
\hline$Q^{-1}{ }_{2}$ & 500 & $1.0 \times 10^{-4}$ & $2.7 \times 10^{-4}$ & $5.8 \times 10^{-4}$ \\
\hline$Q^{-1}{ }_{3}$ & 560 & $1.7 \times 10^{-4}$ & $3.0 \times 10^{-4}$ & $5.0 \times 10^{-5}$ \\
\hline$Q^{-1}{ }_{4}$ & 621 & - & - & $1.9 \times 10^{-4}$ \\
\hline$Q^{-1}{ }_{5}$ & 650 & $3.0 \times 10^{-5}$ & - & $9.0 \times 10^{-5}$ \\
\hline$Q^{-1}{ }_{6}$ & 710 & $1.0 \times 10^{-4}$ & $1.0 \times 10^{-4}$ & $3.5 \times 10^{-5}$ \\
\hline
\end{tabular}

The XRD patterns of the extracted carbides indicate that only $\mathrm{Nb}$-rich carbides $\left(\mathrm{MC}\right.$ and $\left.\mathrm{M}_{2} \mathrm{C}\right)$ are present after the $673 \mathrm{~K}$ heating step. These carbides, which were already present in $\gamma$-field, are retained after quenching and are scarcely affected by treatments in the temperature range of our tests.

The heating step at $773 \mathrm{~K}$ induces the precipitation of the $\mathbf{M}_{7} \mathbf{C}_{3} \mathrm{Cr}$-rich carbides (hexagonal $\mathrm{a}=1.398 \mathrm{~nm}$, $c=0.452 \mathrm{~nm}$ ) whereas the $M_{23} C_{6}$ carbides (cubic $a=1.066 \mathrm{~nm}$ ) start to form only after the $873 \mathrm{~K}$ step. The relative intensities of XRD reflections of $\mathrm{M}_{23} \mathrm{C}_{6}$ and $\mathrm{M}_{7} \mathrm{C}_{3}$ carbides confirm a well known phenomenon, i.e. the precipitation of the former ones takes place at expenses of the latter ones. The average chemical composition of $\mathrm{Cr}$-rich carbides is shown in Tab.2.

Table 2- Average chemical composition of $\mathrm{Cr}$-rich carbides extracted from MANET steel.

\begin{tabular}{|c|c|c|c|c|}
\hline Cr (at.\%) & Fe (at.\%) & Nb (at.\%) & Mo (at.\%) & Type \\
\hline 50 & 45 & 3 & 2 & $M_{7} C_{3}$ \\
\hline 63 & 28 & 4 & 5 & $M_{23} C_{6}$ \\
\hline
\end{tabular}

\section{DISCUSSION}

The IF spectrum evolution following successive heating steps (see fig.1) shows that $\mathrm{C}-\mathrm{Cr}_{\mathrm{n}}$ associates are not stable structures. This phenomenon, which is observed in samples cooled from the $\gamma$-phase with a relatively slow rate $\left(\dot{T}=150 \mathrm{~K} \mathrm{~min}^{-1}\right)$, has been extensively discussed in other papers $[10,11,13]$.

In this work the attention is focussed on an aspect connected to the precipitation of $M_{7} C_{3}$ carbides.

The comparison of IF spectra in fig.1 (a) and (b) (see also Tab.1) shows that the most intense peak after the $673 \mathrm{~K}$ heating step, i.e. the $Q^{-1}$ peak, disappears after the successive step at $773 \mathrm{~K} . M_{7} C_{3}$ carbides form after this treatment $(773 \mathrm{~K}$ ) and EDS microanalysis results (Tab.2) indicate that $\mathrm{Cr}$ atoms are $50 \%$ of the total metal atoms. From the stoichiometric composition it is derived that the ratio between $\mathrm{C}$ and $\mathrm{Cr}$ atoms present in $M_{7} C_{3}$ carbides is about 1:1. Therefore, the formation of $M_{7} C_{3}$ carbides occurs when the $C-C_{1}$ associates, structures with the same ratio between $\mathrm{C}$ and $\mathrm{Cr}$ atoms, cease to give their contribution to relaxation processes. These results suggest that the formation of $\mathrm{M}_{7} \mathrm{C}_{3}$ carbides may take place by aggregation of $\mathrm{C}-\mathrm{Cr}_{1}$ associates. Following the $873 \mathrm{~K}$ heat step $\mathrm{M}_{23} \mathrm{C}_{6}$ carbides form at expenses of $M_{7} C_{3}$ carbides but nucleate on different sites [15]. When $\mathrm{M}_{7} \mathrm{C}_{3}$ carbides solve, $\mathrm{C}-\mathrm{Cr}_{1}$ associates are released in the matrix, can thus participate again to relaxation processes and the $Q^{-1}$, peak is observed in the IF spectrum (c). On the other hand the hypothesis that these carbides form by $C-\mathrm{Cr}_{1}$ aggregation is consistent with the $\mathrm{M}_{7} \mathrm{C}_{3}$ structure described by Dyson and Andrews [16]. The positions occupied by metal and $C$ atoms in the $M_{7} C_{3}$ carbide cell are represented in fig. 2 where different symbols indicate different atomic layers. The complex structure is formed by distorted octahedra having a $\mathrm{C}$ atom at the centre (one of them is indicated). 


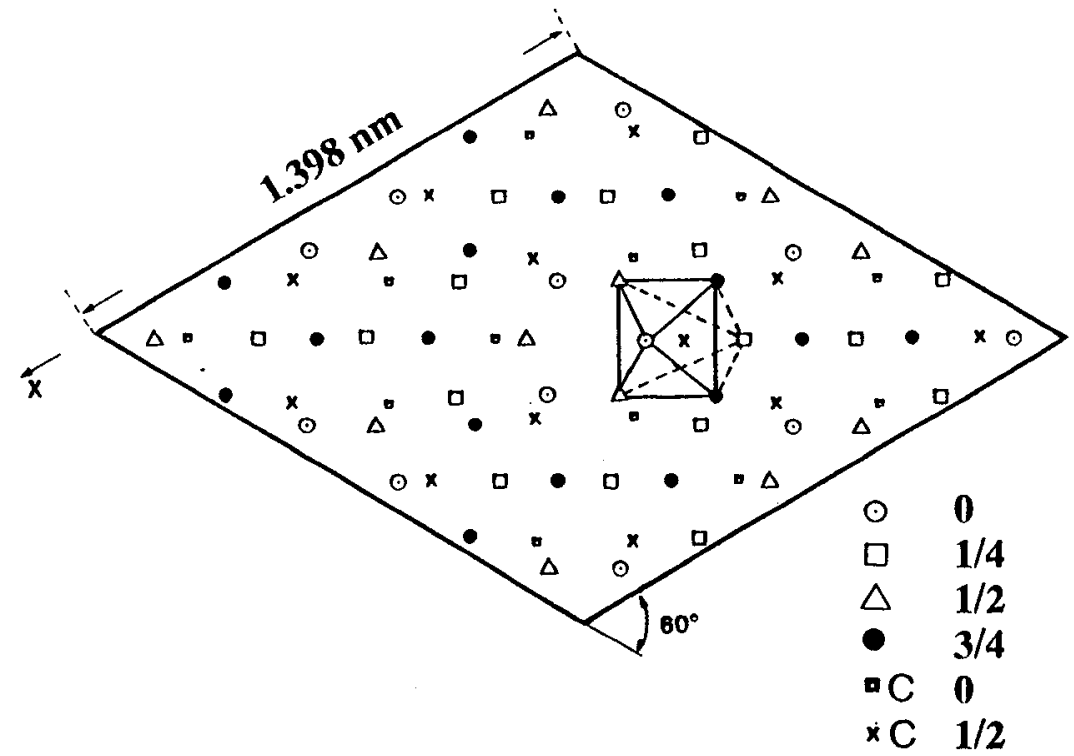

Figure 2- Unit cell of the $\mathrm{M}_{7} \mathrm{C}_{3}$ carbide [16]: $\mathrm{C}$ atoms occupy the centre of a distorted octahedron.

\section{CONCLUSIONS}

The present work has evidenced that remarkable changes in IF spectrum of MANET steel take place when the material is subjected to thermal treatments in the temperature range of $\mathrm{Cr}$-rich carbide precipitation (773-873 K). The formation of $\mathrm{M}_{7} \mathrm{C}_{3}$ carbides is accompanied by the disappearing of the peak due to $\mathrm{C}-\mathrm{Cr}_{1}$ associates, which re-appears when these carbides solve.

On the basis of IF results, of the chemical composition of the extracted carbides and of their crystal structure it is suggested that $\mathrm{M}_{7} \mathrm{C}_{3}$ carbides may form by $\mathrm{C}-\mathrm{Cr}_{1}$ associate aggregation.

\section{ACKNOWLEDGMENTS}

The authors ate grateful to Mr. P. Plini and Mr. B. Iacovone for the assistance in sample preparation.

\section{REFERENCES}

[1] Spooner S., Brundage W.E., Scripta Metall. 17 (1983) 573-574.

[2] Vintaykin Ye.Z., Kolontsov V.Yu, Phys. Met. Metallogr. 26 (1968) 97-100.

[3] Chandra D., Schwartz L.H., Trans. AIME 2 (1971) 511-519.

[4] De Nys T., Gielen P.M., Trans AIME 2 (1971) 1423-1428.

[5] Ha K.F., Zhang H.M., Jing K.L., Metall. Trans. 20A (1989) 2563-2567.

[6] Zhu F., Wendt H., Haasen P., Scripta Metall. 16 (1982) 1175-1182.

[7] Haasen P., Metall. Trans. 16A (1985) 1173-1184.

[8] Gondi P., Montanari R., Physica Stat. Sol. (a) 131 (1992) 465-480.

[9] Gondi P., Montanari R., Coppola R., J. of Nuclear Mater. 191-194 (1992) 1274-1278.

[10] Gondi P., Montanari R., Sili A., Z. für Metallkd. 85 (1994) 664-669.

[11] Gondi P., Montanari R., Sili A., Tata M.E., J. of Nuclear Mater. (in print).

[12] Tomilin I.A., Sarrak V.I., Gorokhova N.A., Suvorova S.O., Zhukov L.L., Phys. Metall. Metallogr. 56-3

(1983) 74-79.

[13] Gondi P., Montanari R., Tata M.E., Materials Letters 25 (1995) 249-255.

[14] Ritchie I.G., Rawlings R., Acta Metall. 15 (1967) 491-496.

[15] Honeycombe R.W.K., Steels Microstructure and Properties (Edward Arnold, London 1990) pp.158.

[16] Dyson D.J., Andrews K.W., J. of The Iron and Steel Institute (1969) 208-219. 